\title{
Un acercamiento teórico sobre la mujer en la seguridad social"
}

\author{
Yaneth Vargas Sandoval**
}

Recibido: 15 de octubre de 2019 • Aprobado: 18 de noviembre de 2019

\section{Resumen}

En el presente artículo se hace un acercamiento teórico sobre la mujer y la seguridad social, haciendo un análisis de autores como Ulrich Beck y Zygmunt Bauman, para quienes la sociedad es una sociedad en riesgo; y planteándose, según Robert Castel, que dicho riesgo puede ser socializado a través de la seguridad social. En lo que respecta a la mujer, se analizarán teorías como las de Nussbaum y Amartya Sen, para quienes se debe abordar las condiciones de las mujeres a través de la teoría de las capacidades. Por su parte, con Nancy Fraser se analizarán las injusticias sufridas por las mujeres, por un lado, de tipo económicas o de redistribución y, por otro lado, culturales o de reconocimiento. Sumado a lo anterior, se analizan las teorías de Winkander y de Federici, con quienes se determinará la división sexual del trabajo, y cómo esta afecta hasta nuestros días los trabajos que desempeñan las mujeres y su no reconocimiento. Por último, se analiza cómo los sistemas de seguridad social replican las inequidades sufridas por las mujeres.

Palabras clave: Mujer. Salario. Seguridad social. Trabajo. Trabajo doméstico.

* El presente artículo es producto del proyecto de investigación institucional "La perspectiva de género, en el Sistema de Pensiones Iberoamericano: Especial Referencia a la Protección de la Vejez", en el marco del programa del Doctorado en Derecho en la Universidad Rey Juan Carlos (España).

Citar como: Vargas Sandoval, Y. (2020). Un acercamiento teórico sobre la mujer en la seguridad social. Revista IUSTA, 52, 77-101. Dor: https://doi.org/10.15332/25005286.5484

** Abogada, Especialista en Derecho procesal de la Universidad Libre, Colombia, Especialista en Docencia Universitaria, Máster en Relaciones Iberoamericanas e Internacionales de la Universidad Rey Juan Carlos, Madrid, España, Máster en Dirección y Gestión de los Sistemas de Sistemas de Seguridad Social en la Universidad Alcalá Henares-oiss, Madrid, España. Postulante a Doctorado en la Universidad Rey Juan Carlos, Madrid, España. Docente de Seguridad Social en la Maestría de la Universidad Tecnológica de Cartagena.y.vargas@alumnos.urjc.es; yvargas@uniboyaca.edu.co. ORCID: 0000-0002- 9188-1477. 


\title{
A THEORETICAL APPROACH TO WOMEN IN SOCIAL SECURITY
}

\begin{abstract}
In this article a theoretical approach is made about women and social security, making an analysis of authors such as Ulrich Beck and Zygmunt Bauman, for whom society is a society at risk; and proposing, according to Robert Castel, that this risk can be socialized through social security. With regard to the women, theories such as those of Nussbaum and Amartya Sen will be analyzed, for whom the conditions of women must be addressed through the theory of abilities. On the other hand, with Nancy Fraser, the injustices suffered by women will be analyzed, on the one hand, of economic or redistribution type and, on the other hand, of cultural or recognition type. In addition to the above, the theories of Winkander and Federici are analyzed, with whom the sexual division of labor will be determined, and how it affects to this day the works performed by women and their non-recognition. Finally, it analyses how social security systems replicate the inequities suffered by women.
\end{abstract}

Keywords: woman, salary, social security, work, domestic work.

\section{UMA APROXIMAÇÃO TEÓRICA SOBRE A MULHER NA SEGURIDADE SOCIAL}

\section{Resumo}

Neste artigo se faz uma aproximação teórica sobre a mulher e a seguridade social, fazendo uma análise de autores como Ulrich Beck e Zygmunt Bauman, para os quais a sociedade é uma sociedade em risco; e expondo, segundo o Robert Castel, que esse risco poder ser socializado através da seguridade social. No que respeita à mulher, se analisarão teorias como as de Nussbaum e Amartya Sem, para os quais se devem abordar as condições das mulheres através da teoria das capacidades. Por sua parte, com Nancy Fraser se analisarão as injustiças sofridas pelas mulheres, por um lado, de tipo econômico ou de redistribuição e por outro lado, culturais ou de reconhecimento. Alem disso, se analisarão as teorias de Winkander e de Federici, com os quais se determinará a divisão sexual do trabalho e como esta afeta até o presente os trabalhos que desempenham as mulheres e seu não reconhecimento. Por último, analisa-se como os sistemas de seguridade social replicam as iniquidades sofridas pelas mulheres.

Palavras-chave: mulher, salário, seguridade social, trabalho, trabalho doméstico. 


\section{Introducción}

El marco teórico de esta investigación se desarrollará a partir de las teorías de autores como los sociólogos Ulrich Beck y Zygmunt Bauman, quienes plantean que la sociedad actual es una sociedad en riesgo (Cortes, 2016), y que el aspecto laboral impacta de manera directa sobre las personas de esta sociedad. Esta teoría se complementa con el desarrollo que hace Robert Castel respecto a la sociedad en riesgo: dado que las personas no pueden vivir siempre en incertidumbre, se requiere una sociedad segura, lo cual, según su teoría, se lograría con la implementación de un sistema de protección social (Barragán, 2016).

Las teorías que se han establecido para superar las injusticias que viven las mujeres en esta sociedad de riesgo también van a ser objeto de análisis. Para ello, se aborda la tesis de Martha Nussbaum, quien, junto a Amartya Sen, estudia la teoría del "enfoque de las capacidades". Adicionalmente se contrasta la teoría de Nancy Fraser sobre las injusticias que viven las mujeres. Estas injusticias se pueden catalogar, según Fraser, en dos tipos: económicas o de redistribución, y culturales o de reconocimiento. Esto permite analizar, en este trabajo, el modo en que las mujeres sufren las dos injusticias antes referidas. Su análisis y tratamiento permitirá plantear posibles soluciones.

De igual manera, teniendo en cuenta que en la presente investigación se hará un estudio de las mujeres y la seguridad social, se requiere hacer un análisis tanto de las condiciones laborales de las mujeres como del modo en que la división sexual del trabajo afecta el reconocimiento del derecho a la pensión. Para ello, se tomarán las teorías de Winkander y de Federici. Con Winkander se puede demostrar que la división sexual del trabajo, surgida en la industrialización, somete a la mujer a condiciones de precariedad en el trabajo. Por su parte, con Federici se evidencia que el sistema capitalista pudo influir de manera directa en la construcción de esta división sexual del trabajo. Del mismo modo, con Federici será importante la crítica, desde el feminismo al marxismo, por no haber tenido en cuenta el trabajo reproductivo de las mujeres que aportan al sistema de capitales (Tirado, Bedoya y Blanco, 2016).

Por último, se abordan directamente los estudios desarrollados con respecto a la mujer y la seguridad social, que, si bien es cierto que son pocos, pueden aportar a esta investigación. La profesora Gabriela Mendizábal, de Equidad de Género y Protección Social en México, hace evidente la problemática de la feminización 
de la vejez. Esto se suma al estudio realizado por Mesa-Lago y Márquez, sobre las reformas de los sistemas de pensiones y asistencia social y el estudio sobre la perspectiva de género en los sistemas de seguridad social en Iberoamérica.

\section{Sociedad, mujer y protección social}

\section{A. Sociedad en riesgo}

En la presente investigación, es necesario hacer un acercamiento a la sociedad en la que se desarrolla la mujer, ya que la sociedad impacta de manera directa el devenir diario de las mujeres; más aún, cuando la presente investigación tiene por objetivo principal analizar, desde la perspectiva de género, cómo afecta el sistema de pensiones en Iberoamérica a la calidad de vida de las mujeres, en el acceso a la pensión de vejez.

La sociedad actual, según el sociólogo alemán Beck (2007), es una sociedad en riesgo o una sociedad de inseguridad (Molina González, 2016). Lo que era considerado seguro, que incluía aspectos como el pleno empleo, pensiones seguras, elevados ingresos fiscales, entre otros, ya no lo es; el trabajo se torna precario; los cimientos del Estado asistencial se vienen abajo (Cortes, 2013); las biografías personales se tornan frágiles; la pobreza de la vejez se programa anticipadamente" (Beck, 2007, pp. 10-11).

Por su parte, Zygmunt Bauman considera que la sociedad actual es una sociedad líquida, en la que se vive en constante incertidumbre, en la que el miedo forma parte del vivir diario (Pardo, 2014). En este orden de ideas, resulta procedente afirmar que la vida es inestable, como las relaciones personales o laborales. El progreso, que en otros tiempos generó seguridad, ahora genera crisis y tensiones continuas (Patarroyo y Benavides, 2014). Por lo que se hace necesario tratar de calcular y minimizar los riesgos (Bauman, 2017, p. 9).

Pero vivir y enfrentar los miedos, o establecer acciones en defensa de estos miedos, lleva a que dichos miedos se concreten. Para Bauman (2017), en esta sociedad en riesgo, "el capital de miedo puede transformarse en cualquier tipo de rentabilidad, ya sea económica o política.” (p. 23). Por esto, la inseguridad social lleva a que la sociedad se modifique drásticamente, tanto en aspectos sociales como económicos. Las nuevas formas de relacionarse en la sociedad, la racionalización 
de las tecnologías de la información, el medio ambiente, entre otros, serán factores a tener en cuenta en esta nueva sociedad (Beck, 1998, p. 256).

La misma posición, frente a la sociedad actual, la plantea el sociólogo francés Robert Castel (2010), para quien “el riesgo se vuelve 'omnipresente' y desemboca en una representación totalizadora de la sociedad contemporánea como una 'sociedad del riesgo', lo cual es otra manera de decir que vivimos tiempos inciertos.” (p. 30). Castel señala que existen otros riesgos específicos en el mundo laboral, como el "riesgo de desocupación y el riesgo de precariedad, que, si bien tampoco son nuevos, sí afectan de manera directa el sistema de protección social” (2010, p. 31).

Otro aspecto para tener en cuenta, en esta sociedad en riesgo, es que en ella se desarrolla un proceso de individualización, a través del cual el Estado y la economía pasan los riesgos a los individuos (Garzón, 2013). Será el individuo ahora quien tendrá que enfrentar, él solo, los riesgos de esta sociedad, por lo que se requieren nuevas instituciones sociales (Valderrama, Téllez y Blanco, 2018). Pero esta individualización afecta aun más a las mujeres, por aspectos como las normas sobre divorcio, que no protegen adecuadamente el poco o nulo acceso a la seguridad social. El trabajo de cuidado, no reconocido como trabajo, lleva a que la invidualización de la sociedad tenga una conexión directa con lo femenino (Valderrama, Téllez y Blanco, 2018, p. 149).

\section{B. Sociedad de seguridad con la seguridad social}

De igual manera, en la presente investigación se requiere el aporte que Robert Castel (2010) hace a la teoría de la sociedad del riesgo, en lo referente a que la sociedad no puede permanecer siempre en la incertidumbre y debe convertirse en una sociedad de seguridad (Saidiza y Carvajal, 2016). Esto se logra "a través de la mutualización de este tipo de riesgos, mediante la tecnología del seguro obligatorio con la garantía del Estado social." (Castel, 2010, p. 30).

La seguridad social es la forma a través de la cual las personas se aseguran a partir del trabajo, la acción estatal a través de los servicios públicos (Forero, 2014). Ello da a las personas acceso a bienes y servicios que no obedecen a la lógica del mercado. Por lo que la seguridad social será una razón de ser del Estado, y la seguridad social debe ser consolidada en la ciudadanía social (Forero, 2014, p. 40).

Robert Castel (2004) amplía su visión de la seguridad social en el texto La Inseguridad Social. ¿Qué es estar protegido?, en el que plantea una concepción más amplia 
de la seguridad social. Castel menciona que la inseguridad social es lo que lleva a que se construya una sociedad de seguridad, en la que se concibe una protección desde el momento en que se nace hasta el momento en que se muere, generando así un acercamiento al concepto de seguridad social (2004, p. 11).

En busca de esa seguridad, los Estados crean instituciones sanitarias y sociales, que protegerán frente a contingencias, tales como la perdida de la salud física o mental, la discapacidad o la vejez (Gallego, 2014). Como indica Castel, estar protegidos desde el punto de vista social significa: "que estos individuos dispongan por derecho de las condiciones sociales mínimas de su independencia. La protección social es así la condición de posibilidad para formar lo que he llamado una sociedad de semejantes." (2010, p. 197).

En estas sociedades aseguradas, un aspecto importante es la pensión de jubilación o de vejez, que se establecerá como una solución a la inseguridad social que enfrenta un trabajador viejo sin la posibilidad de trabajar. De esta manera, se consolida como "un derecho constituido a partir del trabajo", amparando al trabajador cuando ya no trabaja (Castel, 2004, p. 43).

Si bien es cierto que esta forma de asumir la inseguridad social, a través de seguros sociales sustentados por el Estado social, fue un gran avance para la sociedad, en la actualidad, con el desmontaje, eliminación y rebaja de los derechos a la seguridad social, se genera inseguridad e incertidumbre en la sociedad. Así, en palabras de Bauman, "Lo que se conserva de las instituciones actuales, que encarnan la promesa inicial, ya no ofrece la esperanza, ni mucho menos la confianza, de sobrevivir a la futura, e inminente, ronda de recortes" (2017, p. 25).

\section{a. Seguridad social desde el surgimiento del Estado de bienestar}

En una sociedad segura, como lo señala Castel, cuando la sociedad ha superado la inseguridad a través de la seguridad social, se considera que el pueblo no está condenado

[...] a vivir "al día", a merced del más mínimo accidente que pudiera surgir en el camino. Nuestras existencias, ya no se desarrollan, desde el nacimiento, hasta la muerte, sin redes de seguridad una bien llamada "seguridad social" se ha vuelto un derecho para la inmensa mayoría de la población y ha generado una multitud de instituciones sanitarias y sociales. (2004, pp. 11-12) 
Esto se logra por medio del Estado, ya que este es el que debe proveer el bienestar a sus ciudadanos (Blanco y Gómez, 2016).

Desde el punto de vista político, la seguridad social surge del Estado de bienestar de inicios del siglo xx, período en el que Europa se encontraba en posguerra. Ello, sumado a la crisis económica de 1929 y a la consolidación de la Unión Soviética, genera un gran descontento social, así como el cuestionamiento del Estado liberal, que no tendrá respuestas para estas nuevas realidades. Lo anterior hace necesario el surgimiento de un Estado, que pueda tener una relación más directa con la economía y la sociedad. Nos encontramos así ante las propuestas realizadas por John Maynard Keynes y William Beveridge, sentando las bases del Estado de bienestar; Keynes desde el punto de vista económico y Beveridge desde el punto de vista institucional (Mendizábal y Vargas, 2017, pp. 41-70).

A partir de ello, se construye el Estado social de derecho, con la fundamentación de la distribución de la riqueza, de modo que se establecen ya no solo seguros sociales, sino un sistema integral de protección, que cubra toda la población, sin distingo de ser trabajador o no (Mendizábal y Vargas, 2017, p. 50). Actualmente, la seguridad social se desarrolla en Estados sociales, el "Estado social significa también regulación de la economía y garantía de todos los derechos, incluidos los sociales" (Mendizábal y Vargas, 2017, p. 3).

Para autores como Viciano y Martinez, el Estado social, desde lo socioeconómico, se establece en el pacto capital-trabajo. En este: "el capital aceptaba distribuir rentas y garantizaba unos mínimos sociales y de garantías laborales. El Estado asumía un papel regulador del conflicto entre empresarios y obreros, y los trabajadores disminuían la intensidad de contestación al sistema socioeconómico" (Viciano y Martinez, 2010).

Pero, actualmente en Iberoamerica, se están desmontando los beneficios ganados con el surgimiento del Estado de bienestar. Como ha dicho algún autor,

[...] el pensamiento neoliberal asume y justifica que la globalización económica y la internacionalización de los mercados financieros, fuerzan a los gobiernos a seguir unas políticas públicas de adelgazamiento del Estado social con distribucion de la protección social y aumento de la flexibilidad laboral. (Vargas y Bracchi, 2016, p. 5)

La crisis del Estado social, y el no reconocimiento de ciertos derechos, como el de la seguridad social, lleva a que pierda su razón de ser como Estado. "Finalmente, 
no hay Estado social (ni habrá, materialmente, Estado constitucional) sin la plena efectividad y exigibilidad de los derechos sociales." (Vargas y Bracchi, 2016, p. 10).

\section{b. E1 Estado de bienestar debe ser repensado}

A partir de los años 70, comienza la crisis del Estado de bienestar, impactado por aspectos como la globalización, la fuerte influencia del neoliberalismo, las crisis políticas y sociales, entre otros factores. Todo esto lleva a la necesidad de replantear el Estado de bienestar. Según Beck (1998), el replanteamiento debe darse principalmente en el aspecto laboral, ya que el Estado debe dar solución al paro masivo, garantizar las condiciones laborales y el crecimiento de los costes de los salarios, pero en este último evento deberá afrontar a los inversores privados (p. 284).

Para Castel, igual que para Beck, es necesario replantear el Estado social, reformulándolo con respecto a la mundialización y la globalización. Aunque como consecuencia el Estado no tendría la suficiente autonomía para decidir sus políticas económicas y sociales, el autor establece que no debe desconocerse que aun así el Estado sigue siendo la principal instancia política con respecto a las decisiones en materia de política social (Castel, 2010, pp. 36-37).

Si bien es cierto que la seguridad social demanda una visión de construcción del Estado social, este debe garantizarla, pues de lo contrario se estaría en constante inseguridad, siendo el Estado el encargado de definir los sistemas y financiarlos. Como señala Castel "se entiende que los actuales cuestionamientos del Estado social referidos al debilitamiento, incluso al derrumbe de los colectivos debido a la vigorización poderosa de los procesos de individualización, pueden pagarse con un aumento masivo de la inseguridad social." (2004, p. 53).

La reformulacion del Estado pasa por reorganizar el Derecho. Así, para Castel (2010):

En una "sociedad de los individuos", un Estado social activo, o reflexible, implicaría el acercamiento del derecho social con respecto a las situaciones locales y a las trayectorias de las personas. De este modo habría un mejor Estado, y no un menos Estado. (pp. 40-41)

Por ello, se requieren conjuntamente políticas sociales fuertes, como lo hizo Europa occidental al implementar la seguridad social desde lo público y para todos 
los ciudadanos. Pero, en America Latina, la seguridad social se ha implementado con instituciones y leyes hasta hace muy poco tiempo, por lo que aún son estructuras frágiles, que no garantizan adecuadamente los derechos a sus ciudadanos. Al respecto, se puede establecer que "a menudo carecen de medios y corren el riesgo ser desmanteladas por políticas ultraliberales de reducción de gastos públicos y de privatización de los servicios sociales." (Castel, 2010, p. 146).

\section{Acercamiento a los aspectos teóricos de género}

Como ya se ha indicado, dentro de la hipótesis a desarrollar en la presente investigación, se encuentra el cuestionamiento sobre los sistemas de seguridad social, pues estos, al ser neutros y no tener en cuenta el contexto de género, condicionarían el acceso a la pensión de vejez y a la calidad de vida de las mujeres.

El concepto de género surge con los movimientos feministas de Estados Unidos, en los años 70. Estos pretendieron ir más allá de la diferenciación tan solo biológica del sexo mujer/hombre y de lo sexual, que se tenía hasta entonces. Se trataba de alcanzar una concepción más amplia, que implicara una construcción social y una mejor fundamentación de sus luchas por la reivindicación de sus derechos (Scott, 1986).

Para explicar el concepto de género, acorde a las teorías feministas, se analiza desde las perspectivas histórica, psicológica y antropológica, entre otras. Desde el punto de vista histórico, la conceptualización del aspecto teórico de género ha pasado de los orígenes del patriarcado a la teoría marxista, hasta llegar a una teoría de la escuela del psicoanálisis, que explica la producción y reproducción de la identidad de género (Scott, 1986, p. 275).

Se llega así a determinar que el género no es la diferencia natural dada a los hombres y las mujeres de acuerdo con el sexo, sino que el

[...] género pasa a ser una forma de denotar las "construcciones culturales"; esto es, una creación social de ideas sobre los roles apropiados para mujeres y hombres. Es una forma de referirse a los orígenes exclusivamente sociales de las identidades subjetivas de hombres y mujeres. (Scott, 1986, p. 7)

Para la historiadora Scott, la definición, estructurada en las construcciones sociales, se basa en las diferencias de sexo, siendo el género una forma de relación de poder. 
Igual posición se ha desarrollado desde la antropología, con autoras como Marta Lamas (2000), para quien la nueva conceptualización de género "se refiere al conjunto de prácticas, creencias, representaciones y prescripciones sociales que surgen entre los integrantes de un grupo humano en función de una simbolización de la diferencia anatómica entre hombres y mujeres." (p. 45).

Con esta definición se aborda la división sexual del trabajo, las prácticas religiosas y el ejercicio del poder. "La cultura marca a los sexos con el género y el género marca la percepción de todo lo demás: lo social, lo político, lo religioso, lo cotidiano." (Lamas, 2000, pp. 2-3).

En la actualidad, el concepto de género también es utilizado como adjetivo; por ejemplo, la desigualdad de género o la violencia de género. Este uso denota que el género hace referencia indirecta a las mujeres, dentro de la lucha constante por su reconocimiento en la sociedad (Palomar, 2015).

\section{A. Las mujeres en la sociedad actual}

En los últimos años, la autora norteamericana Martha Nussbaum y el autor indio Amartya Sen han desarrollado el concepto de capacidades, a partir de un estudio detallado de la mujer en la sociedad actual, su búsqueda de justicia social y del reconocimiento de sus derechos. En su estudio Las mujeres y el desarrollo humano, Nussbaum señala que

[...] las mujeres carecen de apoyo en funciones fundamentales de la vida humana, en la mayor parte del mundo. Están peor alimentadas que los hombres, tienen un nivel inferior de salud, son más vulnerables a la violencia física y al abuso sexual. (2002, p. 27)

Estas condiciones de inequidad son constantes desde su nacimiento y se prolongan durante su vida, las mujeres "carecen de oportunidades para el juego y para el cultivo de sus facultades imaginativas y cognitivas” (Nussbaum, 2002, p. 27).

Estas situaciones impiden, en muchas ocasiones, que las mujeres participen de forma efectiva en la vida política. A su vez, no participar en política lleva a que su situación se replique: "De ese modo, aun cuando vivan en una democracia constitucional como la de la India, en la cual en teoría gozan de igualdad, en realidad son ciudadanos de segunda clase" (Nussbaum, 2002, p. 31). 
Para Nussbaum (2002), las mujeres no llevan una vida plenamente humana, sino que con frecuencia se les trata no como fines en sí mismas, sino como instrumentos para los fines de otros: "reproductoras, encargadas de cuidados, puntos de descarga sexual, agentes de la prosperidad general de una familia” (p. 28).

Sobre la base de lo anterior, Nussbaum fija su tesis en el enfoque de capacidades, teoría que fue desarrollada junto a Amartya Sen y que se implementó en el Informe sobre desarrollo humano del Programa de las Naciones Unidas para el Desarrollo, a través del cual se evalúa la calidad de vida de las personas.

Nussbaum y Amartya Sen analizan el enfoque de capacidades desde el concepto de justicia. Conforme a su análisis, las capacidades llevan a que la gente tenga las mismas "capacidades para funcionar", es lo que la gente es "capaz de ser o de hacer" (Nussbaum, 2002, p. 40). Amartya Sen señala que este concepto de capacidades es desde donde mejor se puede preguntar acerca de la igualdad y desigualdad social.

Para el reconocimiento de los derechos, desde el punto de vista jurídico, el aporte de Nussbaum (2002) a la teoría del enfoque de capacidades pretende ser la base para los "principios constitucionales centrales que los ciudadanos tienen derecho a exigir de sus gobiernos." (p. 40). De igual manera, recomienda que todos deben tener unas capacidades mínimas, tales como la vida, salud e integridad corporal, sentidos, imaginación y pensamiento, emociones, razón práctica, entre otras.

Respecto del trabajo, Nussbaum (2002) determina que debe ser entendido como un aspecto del ser pensante, "de manera que implique el reconocimiento mutuo de la condición humana." (p. 126). En el caso de las mujeres, muchas veces ocurre que el trabajo que desarrollan no es reconocido, lo que evidencia que, en muchas sociedades, las mujeres carecen de un mínimo básico para el funcionamiento como seres humanos. Por esto, se requiere implementar políticas redistributivas, para que todos los ciudadanos tengan un mínimo de capacidades.

Así mismo, Nussbaum proyecta el enfoque de las capacidades como un funcionamiento verdaderamente humano, asimilado a la dignidad humana, con la que se pretende dar fundamento a la visión de los derechos humanos. Esto se utilizará, en el presente estudio, para abordar el análisis del derecho a la seguridad social de las mujeres como un derecho humano.

Si bien para Nussbaum la solución a los problemas de injusticia social que sufren las mujeres puede ser solucionado a través de la tesis de las capacidades; según Nancy Fraser, el problema de género se establece en dos dimensiones: reconocimiento y 
redistribución. Sus posibles soluciones serían el multiculturalismo y el socialismo (Butler y Fraser, 2016, pp. 24-25).

Fraser comienza analizando cómo las injusticias de las mujeres se presentan de dos maneras: las primeras son socioeconómicas, fundamentadas en la estructura económico-político de la sociedad y evidenciadas en la explotación laboral y la desigualdad económica, al asignarse a las mujeres trabajos indeseables o mal pagados, o al privárseles de un nivel de vida material adecuado (Butler y Fraser, 2016, p. 27). La segunda injusticia es de tipo cultural o simbólica, determinada por "modelos sociales de representación, interpretación y comunicación" (Butler y Fraser, 2016, p. 28), lo que tiene como consecuencia que las mujeres sufran de falta de reconocimiento, falta de respeto o invisibilidad cultural.

Pero estas dos injusticias no se presentan de manera autónoma, sino que están presentes y se refuerzan "dialécticamente la una a la otra" (Butler y Fraser, 2016, pp. 30-31). Las mujeres deben sufrir normas sexistas institucionalizadas por el Estado y la economía, "el resultado es un círculo vicioso de subordinación cultural y económica. Por tanto, para combatir la injusticia de género hace falta cambiar tanto la economía política como la cultura" (Butler y Fraser, 2016, pp. 42-43).

Para Fraser (2017), la solución para las injusticias económicas pasa por la reestructuración política-económica, que denomina "redistribución" (p. 32). $\mathrm{Y}$, frente a la injusticia cultural, plantea la necesidad de un cambio cultural que denomina "reconocimiento". Pero las mujeres que sufren injusticias económicas también sufren injusticias culturales, por lo que, según Fraser, se trata al mismo tiempo de un problema de reconocimiento y de redistribución.

Las soluciones que proponen los autores citados afectan distintos aspectos. Así, el cultural o de reconocimiento debe ser dilucidado a través de soluciones transformadoras; por ejemplo, la deconstrucción feminista permite un reconocimiento constante de los nuevos grupos (Fraser, 2017, pp. 51-60).

Para Fraser, las soluciones económicas o de redistribución se han desarrollado desde los Estados de bienestar liberal, pero no es una solución adecuada, ya que deja intacto el aspecto económico-político. Por lo anterior, la solución sería el socialismo, concebido como un feminismo socialista o socialdemocracia femenina.

Según la teoría de las capacidades, desarrollada por Nussbaum y Amartya Sen, las mujeres deben tener la capacidad de ser y hacer, debe dárseles los elementos adecuados para que se desarrollen, más aún en el mundo del trabajo. Por otro lado, con Fraser se llega a considerar que, en esta investigación, será necesario 
abordar el reconocimiento de las mujeres, a través del multiculturalismo, desde el reconocimiento, y del socialismo feminista, dentro del contexto de lo económico.

\section{B. La división sexual del trabajo}

Un aspecto, que afecta la vida de las mujeres y su derecho a recibir una pensión de vejez, ha sido, laboralmente hablando, las tareas que les han correspondido, solo por el hecho de ser mujeres. Ello tiene como consecuencia que no reciban todos los beneficios de la seguridad social, lo que justifica que, en este punto, se analice el surgimiento y permanencia de la división sexual del trabajo, y sus consecuencias en la vida de las mujeres.

La inserción y la permanencia de la mujer en el mundo laboral han sido complejas. En los inicios de la industrialización, mujeres y hombres trabajaban a la par, sin que se estableciese diferencia alguna, ni en cuanto a salario ni en cuanto a trabajo. Con el desarrollo de la industrialización, y en la actual globalización, se hace evidente que las mujeres no desarrollan las mismas actividades que los hombres, como tampoco reciben el mismo salario por actividades iguales. Esto hace que exista una división sexual del trabajo, que afecta a las mujeres durante toda su vida.

En los últimos años, ha sido la profesora Ulla Wikander quien, en mayor medida, se ha centrado en desarrollar su investigación en el ámbito de las relaciones laborales desde la perspectiva de género. Según esta autora, las mujeres tienen que afrontar una realidad dada por su condición de ser mujer en el mundo del trabajo.

La implementación de la división sexual del trabajo se va a presentar en la economía de mercado del siglo xIx, junto con la sociedad industrializada. "En un nuevo proceso laboral, las mujeres dejaron de ser una fuerza de trabajo de igual valor, y quedaron subordinadas a los hombres" (Wikander, 2016, p. 34). Por esto, la industrialización hizo que las mujeres de bajos recursos se emplearan en trabajos precarios y mal pagados, y que las mujeres de clase media y alta fueran exiliadas al mundo privado de sus hogares.

A finales del siglo xix, las mujeres se convirtieron en una competencia laboral para los hombres, quienes mantenían el estatus de proveedores en sus familias. Los hombres se opusieron de manera directa al trabajo de las mujeres: algunos, por el aumento del desempleo; otros, porque deseaban que sus esposas fueran solo amas de casa; y muchos, porque no podían competir con la mano de obra barata 
de las mujeres. Estas razones llevaron a que los sindicatos aceptaran las diferencias salariales entre hombres y mujeres.

El planteamiento del hombre proveedor se establece desde el punto de vista jurídico, en el constitucionalismo social, que se construye en torno al trabajo asalariado, masculino y público, y que lo determina como una condición de la ciudadanía. Esto no es otra cosa que parte de la división sexual del trabajo, que deja a las mujeres en actividades propias del hogar y tareas de cuidado, y en el plano privado (Prieto, 2015, p. 31).

\section{a. Diferencia en la división sexual del trabajo entre solteras y casadas}

Otro aspecto que va a afectar de manera importante a las mujeres, en el ámbito laboral, va a ser el matrimonio. En el siglo xix e inicios del xx, a las mujeres solteras se les consideraba menores de edad cuando contraían matrimonio, ya que era a partir de ese momento cuando podían ser castigadas por sus esposos, y debían pedirles permiso para realizar trabajos asalariados (Wikander, 2016, pp. 12-13).

Para Wikander, esta influencia del matrimonio, en las actividades laborales de las mujeres, llega a intervenir directamente en las labores de las mujeres, ya que muchas de ellas desarrollaban actividades de criadas hasta el momento en que se casaban, lo que implicaba un aprendizaje previo a sus actividades como casadas. De igual modo, las mujeres solteras debían pensar en la eventualidad de abandonar el empleo durante la maternidad, ya que se les otorgaba el tiempo para el cuidado del hijo, pero no se les reconocía ninguna suma de dinero durante este periodo (Wikander, 2016, p. 27).

En el ámbito de las tareas agrarias, las diferencias entre casadas y solteras no eran tan evidentes. En efecto, en la granja, la sirvienta hacía las mismas actividades que la ama de casa, pero no se tenían claros los periodos de tiempo de trabajo, ya que, al vivir en las granjas, las jornadas laborales eran extenuantes (Wikander, 2016, p. 28).

\section{La mujer en el Estado de bienestar y la seguridad social}

A finales del siglo XIX, surgen los seguros sociales, como mecanismo de protección frente a determinadas necesidades sociales, que se reconocerían solo a los trabajadores. Posteriormente, en Inglaterra, a inicios del siglo xx, Beveridge propuso un 
sistema de protección social que alcanzaría a todos los ciudadanos. Planteado así el sistema de protección social, las mujeres vieron restringidos y condicionados sus derechos simplemente por el hecho de ser mujeres (Guarín, 2013). Está limitación se haría efectiva mediante las normas de familia y de seguridad social, pues lo que hace el Estado de bienestar es reforzar las teorías naturalistas, que planteaban la diferenciación entre sexos.

Bajo estos lineamientos, se hizo una fuerte reglamentación de la sexualidad de la mujer, a través de leyes referentes al matrimonio y a la prostitución. Dentro de las leyes del matrimonio, se reglamentan actividades de índole laboral, entre las que se encuentra que los hombres podían controlar la actividad laboral que podía ejercer la mujer y disponer de su salario. Esto demuestra que estas leyes no permitían una adecuada independencia económica de las mujeres. ${ }^{1}$

\section{A. El trabajo reproductivo y su reconocimiento}

Como se ha visto, con la división sexual del trabajo se relega a las mujeres a las tareas domésticas no remuneradas. La identificación de ese trabajo, como trabajo que aporta a la estructura del sistema capitalista, ha sido estudiada por Silvia Federici, quien en sus investigaciones aborda la necesidad de reconocer y pagar el trabajo doméstico.

Así, en su obra Elpatriarcado del salario. Críticas feministas al marxismo, desarrolla un fuerte cuestionamiento al marxismo, por no reconocer el trabajo doméstico como creador de capital. Al igual que Wikander, Federici señala que, con la introducción del salario familiar en el siglo XIX, dado que se reconoce el salario a los hombres, se crea el "patriarcado del salario", ya que se genera una desigualdad entre hombres y mujeres. Esto dividirá la familia en una parte asalariada y otra no asalariada (2018, pp. 16-17).

\section{a. Surgimiento del trabajo doméstico}

Para Federici, como para Wikander, el trabajo doméstico surge a finales del siglo XIX y comienzos del xx, cuando los países industrializados generaron normas de

1 Conforme a la premisa anterior, ha sido el Estado quien, en ocasiones, ha reforzado la división sexual del trabajo en perjuicio de las mujeres, tanto en el mercado laboral como en la vida privada de los hogares (Wikander, 2016). Esta situación ha perdurado hasta la actualidad, afectando de manera directa el desarrollo laboral y personal de las mujeres. 
derecho laboral, que impactaran de modo directo las fábricas y especialmente los hogares. Como consecuencia de esta situación, las mujeres fueron alejadas de las fábricas, y en tanto no se empleó más su mano obra, se las convirtió en amas de casa, no remuneradas, dependientes y subordinadas a los hombres (Federici, 2018, p. 69).

Para Federici, el trabajo doméstico es una creación del sistema capitalista, que genera, dentro de la organización del trabajo, dos cadenas de montaje: una de producción de mercancías, desarrollada por los hombres; y otra que "produce a los trabajadores", desarrollada por las mujeres desde la casa, señalando que la casa también es un centro de producción (2018, p. 18).

La crítica de Federici a Marx es que no tuvo en cuenta, dentro de su tesis, el proceso de reproducción, ya que son las mujeres quienes producen la fuerza de trabajo. Todos estos procesos y dinámicas históricas tendrán como consecuencia que se invisibilice el trabajo doméstico de la mujer y sea aceptado como natural (Federici, 2018).

Además, ello se suma al hecho de que las mujeres, al no recibir ninguna remuneración por el trabajo doméstico que realizan, cuando se incorporan al mercado laboral, se emplean con más bajos salarios o se someten a realizar aún más trabajo doméstico. Desde que el término mujer se ha convertido en sinónimo de ama de casa, cargamos, vayamos donde vayamos, con esta identidad y con las "habilidades domésticas" que se nos otorgan al nacer mujer. Esta es la razón por la que el tipo de empleo femenino es habitualmente una extensión del trabajo reproductivo, y que el camino hacia el trabajo asalariado a menudo nos lleve a desempeñar más trabajo doméstico (Federici, 2018, p. 35).

\section{b. El reconocimiento del trabajo doméstico como trabajo.}

Un aspecto importante que analiza Federici (2018) es que se debe reconocer el estatus del trabajo doméstico como trabajo, ya que esto permitiría entender la relación de las identidades de género con la producción, "y que amplifica la importancia del principio feminista "lo personal es político” (p. 92).

Sin lugar a dudas, Federici (2018) evidencia que uno de los sectores que más se beneficia actualmente con el trabajo doméstico es el servicio social, que debe ser asumido por el Estado. Esta reivindicación de los servicios sociales será reconocida solo en la medida en que se reconozca el trabajo doméstico como trabajo en sentido estricto (Federici, 2018, p. 42). 
Proponer un salario para el trabajo doméstico desarrollado por las mujeres lleva a que se reconozca que el trabajo de reproducción, crianza de los hijos, cuidado de los inválidos, de los adultos mayores, entre otras muchas actividades es una "responsabilidad social" (Federici, 2018, p. 95).

El trabajo de cuidado ha sido encomendado a las mujeres, quienes tendrán que asumir esta tarea como natural por el hecho de ser mujeres (Federici, 2013). Pero ahora con la globalización, también se desarrolla a escala mundial la división internacional del trabajo reproductivo: los inmigrantes deben servir como niñeras, trabajadoras domésticas y cuidadoras de los mayores (Guarín y Aldana, 2016). Para hacerlo, deben abandonar sus propias familias, incluyendo niños y progenitores ancianos; y emplear familiares u otras mujeres con menos recursos y capacidad económica que ellas mismas, para reemplazarlas en unas tareas de las que ya no se pueden hacer cargo (Federici, 2013, p. 210).

Los inmigrantes evidencian la división internacional del trabajo, pero este rol también beneficia al Estado, ya que "Este desarrollo ha resultado ser muy beneficioso para los gobiernos, al permitir ahorrar miles de millones de dólares, que de otra manera hubiesen tenido que pagar para proporcionar servicios asistenciales a los mayores." (Federici, 2013, p. 209).

Para Federici (2013), que no se reconozca el trabajo doméstico no solo conlleva el hecho de percibir un salario y depender directamente de los hombres, sino que afecta de manera directa las pensiones de las mujeres cuidadoras no remuneradas. $\mathrm{Al}$ respecto, se señala:

Ya que el trabajo de cuidados no es un trabajo reconocido como tal y el sistema de pensiones computa su retribución en función de los años cotizados según una base asalariada, las mujeres que han trabajado como amas de casa a tiempo completo solo pueden obtener una pensión a través de su marido asalariado y no tienen derecho a prestaciones de la seguridad social en caso de divorcio. (Federici, 2013, pp. 213-214)

Según Federici (2013), para mejorar las condiciones de las mujeres se requiere "el reconocimiento del trabajo reproductivo como trabajo, lo que les permitiría reclamar un salario por estas tareas y que los familiares que trabajan como cuidadores no se vean penalizados social ni económicamente por su trabajo" (p. 220). 


\section{B. La seguridad social y el contexto de género}

Teniendo en cuenta que el objetivo general de esta investigación es analizar, desde la perspectiva de género, cómo afecta el sistema de pensiones a la calidad de vida de las mujeres, en este punto se aborda el tratamiento de la seguridad social desde el contexto de género (Humbarita, 2015).

Como se evidenció, desde el surgimiento de los seguros sociales en Alemania con Bismark y la posterior implementación de la seguridad social con Beveridge, fundamentado en la redistribución de la riqueza (Mendizábal y Vargas, 2017), no se ha hecho ninguna diferenciación respecto a la condición de ser mujer, por lo que la inequidad de género comenzará desde el inicio del sistema de seguridad social.

A partir de esa premisa, al amparo de los modelos establecidos por Beveridge y Bismark, se implementó la seguridad social en la gran mayoría de países occidentales. Tal implantación conllevó el desarrollo del sistema de pensiones. Recordemos que el modelo de Bismark requería que, para acceder a la pensión de vejez, se hicieran contribuciones fundamentadas en el salario; y en el de Beveridge, en el que se podían obtener pensiones no contributivas, estas debían estar fundamentadas en la ciudadanía social (Jiménez Lara, Quezada García y Huete García, 2014).

Al no establecer diferencias entre hombres y mujeres, en el ámbito de la seguridad social, se replica la desigualdad generada en el acceso y permanencia de la mujer en el trabajo (Guarín, 2015). Como indica Wikander, esto significa que el sistema refuerza la división sexual del trabajo surgida con la industrialización, y lo que se pretendió por parte del Estado fue reforzar el patriarcado. Ambos aspectos se ven reflejados en los sistemas de pensiones.

En Iberoamérica, la institucionalización de los seguros sociales comienza con un carácter público, hasta llegar a consolidar la seguridad social siempre fundamentada en el Estado social (Llano, 2013), y los sistemas de pensiones implementados son sistemas de carácter público y basados en el reparto. En los años 90, se llevaron a cabo reformas importantes en los sistemas de pensiones, algunas tendentes a reforzar el sistema de pensiones (González, 2014). Por otra parte, algunos Estados decidieron hacer reformas estructurales, creando sistemas privados de pensiones o de capitalización, o complementando los sistemas públicos con sistemas privados de pensiones. Pero debe llamarse la atención acerca del hecho de que ninguna de las reformas establece equidad de género (Lora, 2007, p. 397). 
Para Mesa Lago (2007), la inequidad de género en pensiones, dentro de los sistemas de seguridad social, se traza desde su estructura, al no tener en cuenta las causas externas vividas por las mujeres en cuanto al acceso y permanencia en el trabajo. Pero también se encuentra esta inequidad en el ámbito interno de los sistemas. Ello se manifiesta, por ejemplo, en el hecho de que las mujeres deben retirarse a una menor edad en comparación con los hombres, lo que se añade al hecho de que las mujeres tienen una mayor esperanza de vida, aspectos que no han sido tenidos en cuenta en las reformas de los sistemas de seguridad social (Mesa Lago, 2007, p. 408).

A lo anterior debe añadirse que, cuando se implementaron los sistemas de pensiones privadas, tampoco se consideró el contexto de género, por lo que los sistemas privados de protección reafirman la inequidad de género. Entre otros aspectos, se exige un mínimo de cotizaciones para acceder a la pensión mínima y esta cotización se basa en las cotizaciones de toda la vida, lo que requiere permanencia en el mercado laboral, situación muchas veces ajena a las mujeres, ya que ellas detienen su vida laboral por cuidado de hijos o familiares cercanos. También aplican tablas actuariales diferenciadas por género, que conlleva una menor pensión para las mujeres, pues ellas tienen una mayor esperanza de vida (González, 2016; Mesa Lago, 2007, pp. 408-409).

La situación de la mujer, en relación con la seguridad social, ha sido poco analizada, pero se puede aportar a este estudio la investigación realizada en México por Gabriela Mendizábal (2014), quien en una obra colectiva, denominada Equidad de género y la protección social, hace un acercamiento al tema, señalando que en México el proceso de envejecimiento es femenino (p. 118).

Así mismo, esta autora esboza que, en relación con las pensiones de seguridad social, las mujeres deben estar vinculadas laboralmente, o con una relación matrimonial, para acceder a una pensión de sobreviviente. De acuerdo con la evidencia en México:

Una gran mayoría de mujeres pertenecientes a una generación, en la cual se las consideraba en un rol pasivo de madres abnegadas y dedicadas al hogar. También tomamos en cuenta que hubo mujeres de la generación citada que se incorporaron, con salarios muy bajos, y que actualmente, y como resultado de lo anterior, también carecen de prestaciones sociales y/o pensiones contributivas. La pobreza, la discriminación y la marginación pueden añadirse a la vejez en la sociedad mexicana, 
por lo que habría que incorporar los mecanismos necesarios que posibiliten una vivencia más activa y satisfactoria de los adultos mayores. (Mendizábal, 2014, p. 118)

Otro estudio a tener en cuenta es el desarrollado por la Asociación Iberoamericana de la Seguridad Social, donde se hace evidente que la población iberoamericana está envejeciendo mucho más en la población femenina (Jiménez Lara et al., 2014). Del mismo modo, se señala que la división sexual del trabajo persiste en la actualidad y afecta directamente a las mujeres, ya que deben desarrollar labores domésticas y de cuidado no remuneradas. Esto hace que no puedan realizar cotizaciones a los sistemas de pensiones, o lo hagan de manera deficiente, por lo que no podrán acceder a su propia pensión. La mujer en esta situación quedará bajo la dependencia de su cónyuge o compañero, colocándose en situación de vulnerabilidad y de pobreza en la vejez (Jiménez Lara et al., 2014).

Por su parte, el trabajo doméstico o como cuidadoras no remunerado afecta de manera directa la participación de las mujeres en el mercado laboral formal e informal, ya que, si bien las mujeres que acceden a trabajos fuera del ámbito familiar no abandonan sus actividades domésticas, por el contrario, los hombres no han aumentado su participación en estas tareas (Ballesteros, 2015).

Esta situación se agrava por el aumento de la demanda de cuidados de larga duración, dado el envejecimiento demográfico; lo que, unido al hecho de que no existen sistemas públicos de cuidado en los países iberoamericanos o no son de calidad, conlleva que las mujeres abandonen sus trabajos o que trabajen a tiempo parcial. Esto determina que tanto las pensiones de estas mujeres como sus condiciones económicas se vean seriamente afectadas en la vejez (Jiménez Lara et al., 2014).

Las consideraciones antes mencionadas ponen de manifiesto la necesidad de incluir, en los sistemas de seguridad social, el contexto de género, a fin de reconocer de manera particular los trabajos específicos desempeñados por las mujeres, la brecha salarial que sufren, su esperanza de vida, entre otros factores (García, 2013). Todo ello determina que la pensión de jubilación deba ser caracterizada de una forma diferente; sin olvidar, además, que las desigualdades existentes, en el momento de acceder a la pensión de vejez, se mantienen a lo largo de la vida de la pensionista (Arber y Ginn, 1996, p. 171).

En suma, un sistema de seguridad social equitativo, desde la perspectiva de la igualdad por razón de género, exige que se supere el modelo de división sexual del trabajo (Quiroz, 2014), en el que las mujeres son relegadas a las tareas domésticas y 
de cuidado no remuneradas. Para ello, los Estados deberán no solo tener en cuenta los trabajadores que realizan cotizaciones a los sistemas de pensiones, sino también "la provisión de las tareas del ámbito del cuidado" (Jiménez Lara et al., 2014).

\section{Conclusiones}

En el presente artículo, se pudo evidenciar que tanto las mujeres como los hombres, en la actualidad, viven en una sociedad en riesgo, como lo plantea Beck. Esta es la misma condición planteada por Bauman como una sociedad liquida. Ambos evidencian que esta sociedad es una sociedad en constante riesgo, con trabajo precario, pobreza en la vejez, pensiones inseguras y desmonte del Estado asistencial.

Aun cuando una de las razones de ser del Estado social es socializar el riesgo mediante el aseguramiento, como lo plantea Robert Castel, y aun cuando el Estado de bienestar se fundamenta en la institucionalidad de la seguridad social, en la actualidad, con los desmontes de los programas sociales, las imposiciones de multinacionales en el ámbito laboral llevan a que deba ser repensado el Estado social.

Un aspecto que puede concluirse de la presente investigación es que, desde que se hace una división sexual del trabajo de las mujeres, se relega a las mujeres al ámbito privado, a actividades muchas veces no remuneradas, lo que genera una gran desventaja en las relaciones social y laborales. Esta situación ha permanecido durante mucho tiempo y se repite en la actualidad.

Los aportes teóricos de autores como Martha Nussbaum y Amartya Sen, con la teoría de las capacidades que fundamenta los derechos humanos de las mujeres, y como Nancy Fraser, con la propuesta de solucionar el problema de redistribución y reconocimiento que sufren las mujeres a través del Estado de bienestar y el multiculturalismo, aportan sin lugar a duda a una nueva construcción teórica frente a la realidad vivida por las mujeres.

Finalmente, con autoras como Wikander, se constató que, a finales del siglo xix, la mujer sufría la división sexual del trabajo, lo que ponía a los hombres como proveedores de la familia, mientras a las mujeres se les relegaba a la casa y a trabajos de cuidado. Esto se corrobora desde el punto de vista teórico de Silvia Fedirici. Todos estos aspectos se replican en la construcción de los sistemas de seguridad social. 


\section{Referencias}

Arber, S. y Ginn, J. (1996). Relación entre género y envejecimiento: Enfoque sociológico (Pablo Manzano Bernárdez, trad.). Madrid, España: Narcea SA.

Ballesteros, C. (2015). La mujer y el ejercicio efectivo del poder en Colombia, una cuestión de derechos humanos. Revista Verba Iuris, 33, 61-76. Recuperado de https://revistas. unilibre.edu.co/index.php/verbaiuris/article/view/27/24

Barragán, D. (2016). La construcción de la mentalidad democrática como necesidad en el posconflicto. Revista Via Inveniendi et Iudicandi, 11(1), 37-57.

Bauman, Z. (2017). Tiempos Líquidos. Vivir en una época de incertidumbre. Barcelona, España: Tusquets Editores.

Beck, U. (1998). La sociedad del Riego. Hacia una nueva modernidad. Barcelona, España: Paidós.

Beck, U. (2007). Tiempos Líquidos. Vivir en una época de incertidumbre. Barcelona, España: Paidós.

Blanco, C. y Gómez, D. (2016). Constitución política e integración andina desde las nociones de soberanía y democracia. En N. E. Pardo Posada (Ed.), Perspectivas críticas del derecho constitucional colombiano (pp. 107-125). Bogotá, Colombia: Universidad Libre.

Butler, J. y Fraser, N. (2000). ¿̨Reconocimiento o redistribución? Un debate entre marxismo y feminismo. Madrid, España: Traficantes de Sueños.

Castel, R. (2004). La inseguridad social. ¿̇ué es estar protegido? Buenos Aires, Argentina: Manantial.

Castel, R. (2010). El ascenso de las incertidumbres. Trabajo, protecciones, estatuto del Individuo. Buenos Aires, Argentina: Fondo de Cultura.

Cortes, S. (2013). La globalización económica y los derechos humanos. Revista Via Inveniendi et Iudicandi, 8(2), 45-79.

Cortes, S. (2016). Derechos humanos en las políticas de paz y posconflicto en Colombia. Revista Via Inveniendi et Iudicandi, 11(1), 129-145. Recuperado de http://revistas. usantotomas.edu.co/index.php/viei/article/view/2926/2798

Federici, S. (2013). Revolución en punto cero. Trabajo doméstico, reproducción y luchas feministas. Madrid, España: Traficantes de Sueños. 
Federici, S. (2018). Elpatriarcado del salario. Críticas feministas al marxismo. Madrid, España: Traficantes de Sueños.

Forero, J. (2014). El valor superior de la Justicia en la Unión Europea. Especial referencia al Estado Constitucional Social y Democrático de Derecho Español. Revista Verba Iuris, 31, 91-114. Recuperado de https://revistas.unilibre.edu.co/index.php/verbaiuris/ article/view/59/53

Fraser, N. (2017). Los Derechos de Fenerro. Madrid, España: Traficantes de Sueños.

Gallego, J. (2014). Paradoja y complejidad de los derechos humanos en la sociedad moderna. Sentido y comunicación. Revista IUSTA, 40, 143-165.

García, L. (2013). El contexto de mujer en la realidad jurídico-penal colombiana: delitos sexuales y revictimización. Revista IUSTA, 38(1), 103-113.

Garzón, E. (2013). Globalización del derecho, fetichismo legal el velo de los Derechos Humanos. Revista Verba Iuris, 30, 56-89.

González, O. (2014). La Corte Constitucional como agente del campo jurídico colombiano: la omisión legislativa de principios constitucionales. Revista IUSTA, 41(2), 123-137.

González, O. (2016). La omisión legislativa como hecho generador de la responsabilidad patrimonial del Estado. Revista Verba Iuris, 35, 41-63. Recuperado de https://revistas. unilibre.edu.co/index.php/verbaiuris/article/view/5/2

Guarín, E. (2013). Persona y realización efectiva de derechos. Revista IUSTA, 38(1), 133-154.

Guarín, E. (2015). Una aproximación filosófico-jurídica al sentido de la expresión: "Realización efectiva de los derechos". Revista Verba Iuris, 34, 147-159. Recuperado de https:// revistas.unilibre.edu.co/index.php/verbaiuris/article/view/16/14

Guarín, E. A. y Aldana, J. (2016). Estado jurisdiccional y bien común. Revista Verba Iuris, 11(36), 13-26.

Humbarita, J. (2015). Derecho Constitucional Hispanoamericano frente a la realidad institucional, manifiesta divergencia. Revista IUSTA, 43(2), 34-56.

Jiménez Lara, A., Quezada García, M. Y. y Huete García, A. (2014). Estudio sobre la perspectiva de género en los sistemas de seguridad social en Iberoamérica. Madrid, España: oiss. Recuperado de https://oiss.org/wp-content/uploads/2000/01/LA_PERSPECTIVA_DE_GENERO_OISS_2014.pdf 
Lamas, M. (2000). Diferencias de sexo, género y diferencia sexual. Cuicuilco. Revista de ciencias antropológicas, 7(18), 1-25.

Llano, J. (2013). Prácticas jurídicas locales desde los actores del conflicto armado en Colombia. Revista IUSTA, 39(2), 257-287.

Lora, E. (coord.). (2007). El estado de las reformas del Estado en América Latina. Washington, Estados Unidos: Banco Mundial; Mayol Ediciones S.A.

Mendizábal, G. (2014). Equidad de género y protección social. Ciudad de México, México: Porrúa.

Mendizábal, G. y Vargas, Y. (2017). Historia de la seguridad social en Colombia y México. Revista de Derecho Laboral y Seguridad Social de Chile, Vol 34(1), 41-70.

Mesa Lago (2007). Los derechos de género en el S XXI. Madrid, España: Traficantes de Sueños.

Molina González, Y. (2016). Derecho penal del enemigo y dignidad humana. Revista Verba Iuris, 11(36), 135-146.

Nussbaum, M. (2002). Las mujeres y el desarrollo humano. El enfoque de las capacidades. Barcelona, España: Universidad de Cambridge.

Palomar, C. (2015). El vacío del género. Asparkía, 26, 17-33.

Pardo, N. (2014). Un recorrido por los derechos colectivos en la jurisprudencia argentina. Revista Via Inveniendi et Iudicandi, 9(1), 32-49. Recuperado de http://revistas.usantotomas.edu.co/index.php/viei/article/view/1338/1540

Patarroyo, S. y Benavides, P. (2014). Rupturas asignificantes: Revisiones críticas en torno al derecho. Revista Via Inveniendi et Iudicandi, 9(1), 7-31.

Prieto, C. (2015). Trabajo, cuidados, tiempo libre y relaciones de género en la sociedad española. Madrid, España: Editoriales Cínca SA.

Quiroz, M. (2014). Acercamiento a las “oposiciones paradigmáticas” entre neoconstitucionalismo y positivismo jurídico. Revista IUSTA, 41(2), 77-97.

Saidiza, H. y Carvajal, J. (2016). Crisis del Estado de derecho en Colombia: un análisis desde la perspectiva de la legislación penal. Revista IUSTA, 44(1), 17-39.

Scott, J. (1986). El género: una categoría útil para el análisis histórico. American Historical Review, 91, 1053-1075. Recuperado de https://www.fundacionhenrydunant.org/images/ stories/biblioteca/derechos_economicos_sociales_culturales_genero/E1\%20Genero\%20 Una\%20Categoria\%20Util\%20para\%20el\%20Analisis\%20Historico.pdf 
Tirado, M., Bedoya, J. y Blanco, A. (2016). Bioética y transhumanidad: Hacia una aproximación al consumo de sustancias nootropicas en el campo académico. En Carreño Dueñas, D. et al., Bioética y Docencia (pp. 91-117). Bogotá, Colombia: Ibáñez. Recuperado de https://repository.usta.edu.co/handle/11634/1527

Valderrama, I., Téllez, R. y Blanco, C. (2018). La incertidumbre de las victimas dentro del acuerdo para la construcción de una paz estable y duradera. En Carvajal Martínez, J. E. (Comp.), Tendencias actuales de los Derechos Humanos y el Derecho Internacional Humanitario en Colombia (pp. 83-103). Recuperado de https://repository.usta.edu.co/ handle/11634/13049

Vargas, Y. y Bracchi, C. (2016). La mujer latinoamericana dentro del contexto de los Derechos Humanos: énfasis desde la perspectiva del derecho al trabajo. Revista IUSTA, 44(1), 56-78.

Viciano, R. y Martínez, R. (2010). Los procesos constituyentes latinoamericanos y el nuevo paradigma constitucional. IUS. Revista del Instituto de Ciencias Jurídicas de Puebla, 25, 7-29.

Wikander, U. (2016). De criada a empleada. Poder, sexo y división del trabajo (1789-1950). Madrid, España: Siglo XXI. 